\title{
Temporal Genetic Mapping in the Blue-green Alga Anacystis nidulans Using Ethyl Methanesulphonate
}

\author{
By S. F. DELANEY AND N. G. CARR \\ Department of Biochemistry, University of Liverpool, Liverpool L69 $3 B X$
}

(Received 30 September 1974; revised 24 January 1975)

\begin{abstract}
SUMMARY
Cultures of the blue-green alga Anacystis nidulans were synchronized with respect to DNA synthesis as well as cell division. Application of ethyl methanesulphonate at different stages of replication resulted in a peak of mutation frequency for different genetic markers; this peak can be accounted for in terms of the involvement of repair processes. A temporal map of I9 markers has been constructed by this method. Comparison of gene position obtained by temporal mapping indicates that either bidirectional replication or unidirectional replication from more than one origin occurs.
\end{abstract}

\section{INTRODUCTION}

Although genetic mapping by conventional processes involving gene transfer is possible in a number of prokaryotes, methods for determining gene sequence have been developed which do not depend directly on any gene transfer mechanism. These are based on the estimation of marker frequencies by transformation (Yoshikawa \& Sueoka, r963; Sabatier, Louarn \& Sicard, 1972), analysis of density-labelled transducing phage (Caro \& Berg, I968; Nishioka \& Eisenstark, 1970), nucleic acid hybridization (Cutler \& Evans, I967; Bird et al. 1972), studies on the rates of induced enzyme synthesis (Masters \& Pardee, 1965), and mutation induction (Stonehill \& Hutchison, I966; Cerdá-Olmedo, Hanawalt \& Guerola, I968; Vielmetter, Messer \& Schütte, 1968). These methods have made possible the construction of genetic maps of organisms with no known mechanism of gene transfer, for example Streptococcus faecalis (Stonehill \& Hutchison, 1966), and since these techniques depend on replication of the genome they have, in conjunction with conventional genetic mapping, enabled the mode of replication to be determined (Hohlfeld \& Vielmetter, 1973).

Asato \& Folsome (1970) produced a temporal genetic map of Anacystis nidulans for six markers using $N$-methyl- $N^{\prime}$-nitro- $N$-nitrosoguanidine (NTG) for sequential mutagenesis while Herdman, Faulkner \& Carr (1970) located the position of a gene specifying nitrate reductase by u.v. mutagenesis. This communication describes an extension of these studies and the construction of a temporal genetic map of $A$. nidulans for 19 markers. The mutagen was ethyl methanesulphonate (EMS), one which had not been used previously for temporal genetic mapping. Because EMS can readily be inactivated by sodium thiosulphate (Loveless, I959) and thus the exposure time carefully controlled, its use offers an advantage over many other chemical mutagens whose action can only be terminated either by dilution below an effective level or by harvesting and washing the mutated culture. The latter procedures tend to give inaccurate exposure times. 
Table I. Mutant strains of Anacystis nidulans

\begin{tabular}{|c|c|c|}
\hline Strain & Genotype & Phenotype \\
\hline I I 14 & nitB2 & Requires ammonium chloride ( $7 \mathrm{~mm}$ ) \\
\hline I I 2 I & cys $-I$ & Requires cysteine $(0.5 \mathrm{~mm})$ or sodium thiosulphate $(0.1 \mathrm{~mm})$ \\
\hline II 4 I & bio- $I$ & Requires biotin $(2 \mu \mathrm{g} / \mathrm{ml})$ \\
\hline I I 42 & bio-2 & Requires biotin $(2 \mu \mathrm{g} / \mathrm{ml})$ \\
\hline I 172 & $m e t-4$ & Requires methionine (O.I mM) \\
\hline 2 III & nitAI, str-I & $\begin{array}{l}\text { Requires sodium nitrite }(2 \mathrm{mM}) \text { and is resistant to streptomycin } \\
(25 \mu \mathrm{g} / \mathrm{ml})\end{array}$ \\
\hline 2113 & nit $A$, met -2 & Requires sodium nitrite ( $2 \mathrm{~mm})$ and methionine ( $0.1 \mathrm{~mm})$ \\
\hline
\end{tabular}

\section{METHODS}

Organisms. The wild type (oroo) was Anacystis nidulans, strain No. 625 of the Culture Collection of Algae, Department of Botany, Indiana University, Bloomington, Indiana, U.S.A. The mutant strains derived from oI00 are described in Table I. All were revertible by EMS. Stocks of the wild type and mutants were maintained as described by Herdman, Delaney \& Carr (1973).

Cyanophage AS-I, lytic against A. nidulans, was the gift of Dr R. S. Safferman, Office of Research and Monitoring, Environmental Protection Agency, Cincinnati, Ohio 45226, U.S.A. Stocks were propagated in liquid cultures of the host organism. Anacystis nidulans was grown on modified Allen's medium (Herdman et al. 1973) in Roux bottles at $34{ }^{\circ} \mathrm{C}, 8 \mathrm{~cm}$ from banks each of three $40 \mathrm{~W}$ warm white fluorescent lamps, and was gassed with a mixture of air: $\mathrm{CO}_{2}(95: 5, \mathrm{v} / \mathrm{v})$. When the culture density had reached about $10^{8}$ organisms/ $\mathrm{ml}$ the culture was infected with $10 \mathrm{ml}$ of phage lysate, which resulted in complete lysis after $24 \mathrm{~h}$. Cell debris was removed by centrifuging at $3000 \mathrm{~g}$ for $20 \mathrm{~min}$, and after sterilization by filtration the lysate was stored at $0^{\circ} \mathrm{C}$. Lysates prepared in this way remained active for up to one month. Plaque-forming units were assayed by a modification of the procedure described by Safferman \& Morris (1964). To prepare top layers, $2.5 \mathrm{ml}$ of an overnight culture of the host, prewarmed to $48^{\circ} \mathrm{C}$, and $0^{\circ} \mathrm{I} \mathrm{ml}$ of phage lysate, suitably diluted in medium which had been equilibrated with $\mathrm{CO}_{2}$, were added to $2.5 \mathrm{ml}$ of $\mathrm{I} \cdot 2 \%$ (w/v) agar (without medium) held molten at $48{ }^{\circ} \mathrm{C}$. Plates were incubated as described by Herdman et al. (I973) and scored after $48 \mathrm{~h}$; plaque counts were determined in triplicate.

Growth and induction of synchrony. Synchronized growth was induced by light deprivation as described by Herdman et al. (1970). Organisms were grown in a I 1 glass fermentation vessel, immersed in a transparent water bath at $38{ }^{\circ} \mathrm{C}$, illuminated by two $75 \mathrm{~W}$ tungsten lamps (Cryselco, Kempton Works, Bedford) at a distance of $14 \mathrm{~cm}$, and gassed with a mixture of air: $\mathrm{CO}_{2}(95: 5, \mathrm{v} / \mathrm{v})$. The fermentation vessel was a I 1 flat-bottomed reaction vessel (Quickfit, Gallenkamp, London) fitted with a multi-socket flat flange. When the culture density had reached $5 \times 10^{7}$ organisms $/ \mathrm{ml}$, the culture was subjected to a $16 \mathrm{~h}$ dark induction period. On return to normal growth conditions synchronized growth was initiated.

Estimation of cell numbers. Total cell numbers were determined using either a Neubauer counting chamber (Hawksley Crystalite, Gallenkamp) or a model ZB Coulter counter (Coulter Electronics, Dunstable, Bedfordshire) with a $70 \mu \mathrm{m}$ orifice.

Measurement of DNA. DNA was estimated in $20 \mathrm{ml}$ samples from synchronized cultures by the diphenylamine reaction of Burton (1956) modified according to Craig, Leach \& Carr (1969).

Sequential mutagenesis. Samples (Io $\mathrm{ml}$ ) from synchronized cultures were harvested by 
aseptic filtration through cellulose nitrate filters (Sartorious, V. A. Howe \& Co. Ltd, London) with a pore size of $0.45 \mu \mathrm{m}$, and suspended in $10 \mathrm{ml}$ of a sterile solution of 0.2 $\mathrm{M}$-EMS in $0.03 \mathrm{M}$-phosphate buffer $\mathrm{pH} 7.0$. Exposure was at room temperature for $25 \mathrm{~min}$, with the exception of strains I I4I and I I 42 which were much more resistant to the mutagen and were exposed for 60 min. Mutagenesis was terminated by the addition of $\mathrm{I} \mathrm{ml}$ sodium thiosulphate $(50 \%, \mathrm{w} / \mathrm{v})$ after which the organisms were harvested, washed with distilled water and resuspended in $5^{\circ} 0 \mathrm{ml}$ distilled water. The resuspension was inoculated into $50 \mathrm{ml}$ growth medium, supplemented as necessary, in a $250 \mathrm{ml}$ conical flask, and was incubated in an orbital shaker as described by Herdman et al (I973) to permit the segregation of mutant organisms. When the culture density had reached between $\mathrm{I} \times 10^{8}$ and $5 \times 10^{8}$ organisms $/ \mathrm{ml}$, the total cell count was determined and samples were plated on selective medium to score for the marker concerned and on propionate-supplemented medium to score for the standard marker, propionate resistance. In most cases samples were plated undiluted. However, mutation to propionate resistance and phage resistance occurred at a higher frequency than usual, and for these, samples were diluted five-fold before plating. Plates were incubated as described by Herdman et al. (1973) for 7 days, except where propionate resistance and phage resistance markers were being mapped when plates were scored after 5 days' incubation.

Scoring of mutants. Selection was made either for resistant mutants or for revertants of auxotrophic strains. Mutation frequencies were expressed as the number of mutants/10 survivors. Yellow, blue and filamentous mutants could not be selected and were scored among the propionate-resistant mutants and the frequencies of these were expressed as mutants $/ \mathrm{IO}^{3}$ propionate-resistant mutants. It was assumed that scoring mutations in this way did not skew marker positions towards the propionate resistant marker. Phageresistant mutants were scored by a modification of the cyanophage assay technique described above. Top layers were prepared by adding $2.5 \mathrm{ml}$ of concentrated phage lysate $\left(4 \times 10^{6}\right.$ plaque-forming units $\left./ \mathrm{ml}\right)$, prewarmed to $48^{\circ} \mathrm{C}$, and $0 . \mathrm{I} \mathrm{ml}$ of the segregated culture to $2.5 \mathrm{ml}$ of molten agar. These were poured on to agar plates and after incubation phage resistant colonies could be counted.

Chemicals. Ethyl methanesulphonate and polymyxin B sulphate were obtained from Sigma. Polymyxin was used at $\mathrm{I} 50 \mu \mathrm{g} / \mathrm{ml}$, streptomycin at $25 \mu \mathrm{g} / \mathrm{ml}$ and sodium pyruvate at $5 \mathrm{~mm}$. Concentrations of supplements are given in Table $\mathrm{I}$.

\section{RESULTS}

\section{Growth of synchronized cultures}

During the post-induction period all strains examined exhibited a stepwise increase in total cell numbers. The pattern of growth was the same in all strains and was similar to that described by Herdman et al. (I970) for the wild type. Synchronized growth of strain 2I I I (nit AI, str-I) is shown in Fig. I. During synchronized growth, synchronized DNA synthesis (Fig. 2) was observed and this also followed the pattern described by Herdman et al. (1970).

\section{Growth rates in synchronized and exponential cultures}

Under the same conditions of incubation growth rates were faster during synchonized growth than during exponential growth, as shown in Table 2. 


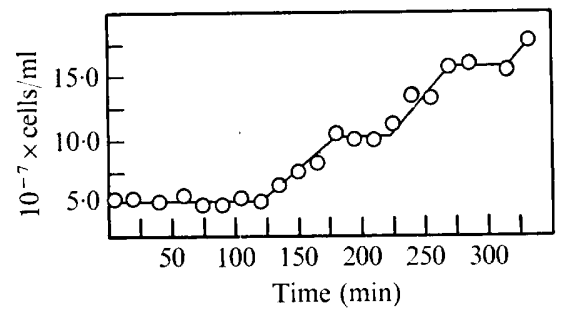

Fig. I. Increase in total numbers of Anacystis nidulans strain 2 I I I (nitAI, str-I) following synchronization.

Table 2. Growth rates (doublings/h) of synchronized and exponential cultures of Anacystis nidulans

Growth rates of synchronized cultures were determined from the beginning of the first and second division periods.

\begin{tabular}{lcc} 
Strain & \multicolumn{2}{c}{ Growth rate } \\
O I00 (wild type) & 0.37 & 0.5 I \\
I I I I (cys-I) & 0.26 & 0.50 \\
I I 72 (met-4) & 0.25 & 0.50 \\
2 I I (nit AI, Str-I) & 0.36 & 0.57
\end{tabular}

Kinetics of mutation induction during synchronized growth

Sequential mutagenesis with EMS resulted in a peak of mutation frequency (Fig. 2) similar to that observed for NTG in Escherichia coli (Cerdá-Olmedo et al. 1968) and Neisseria meningitidis (Jyssum, 1969). Asato \& Folsome (1970) found that NTG produced a peak of mutation frequency in $A$. nidulans, but this was caused by a stepwise increase in mutation frequency which later decreased as the culture divided. However, the peak resulting from EMS mutagenesis cannot be explained in this way since irrespective of whether the absolute number of mutants or the mutation frequency was determined, a peak rather than a stepwise increase was observed (Fig. 2). This suggests that the mutagen acts preferentially at the replication fork (Cerdá-Olmeda et al. 1968), the peak corresponding to the replication of the gene. While a peak of mutation frequency was observed, mutagenesis during DNA replication did not detectably alter survival (Fig. 3); thus only the mutagenic effect of EMS and not the lethal effect was enhanced at the replication fork.

Mapping by reference to a standard marker. Since auxotrophic markers were mapped in different strains it was necessary to establish that the pattern of DNA replication was the same in all strains. For this a standard marker, propionate resistance, was mapped in each experiment as a control. This showed a peak in mutation frequency I 2 minutes after the initiation of synchronous growth, corresponding to the $37^{\text {th }}$ minute of DNA synthesis (Fig. 2). The constancy of this peak showed not only that the pattern of replication was the same in each strain but also that the DNA synthesis period occupied a constant position in the synchronized growth cycle.

The temporal genetic map of Anacystis nidulans. Sequential mutagenesis of synchronized cultures for the different markers is shown in Figs. 2, 3 and 4. Figure 5 shows the temporal genetic map of $A$. nidulans. Map positions were indicated by peaks in the mutation frequency curves. As a peak represents the mode of a curve rather than the mean, the error on the 


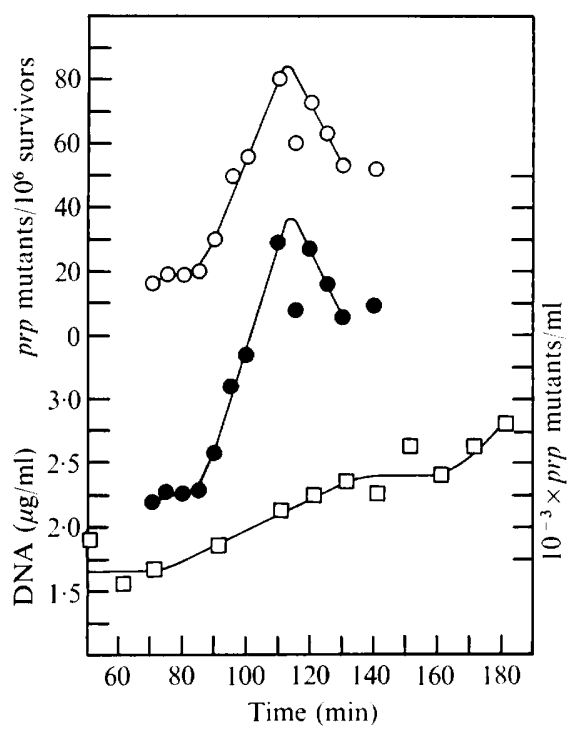

Fig. 2
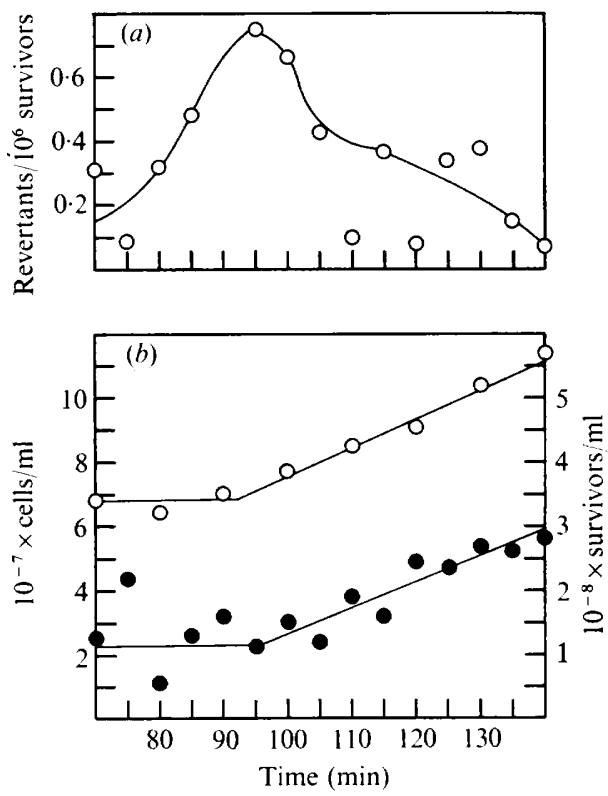

Fig. 3

Fig. 2. Induction of propionate-resistant mutants of Anacystis nidulans by sequential mutagenesis during DNA replication ( $\square$ ) following synchronization. The first replication cycle occupies the period 75 to $135 \mathrm{~min}$ after induction. This is followed by a period of $30 \mathrm{~min}$ during which no synthesis occurs, after which a second replication cycle begins at I $65 \mathrm{~min}$. $\bigcirc$, Mutants $/ \mathrm{I}^{6}$ survivors; , mutants/ml.

Fig. 3. The effect of sequential mutagenesis of a synchronized culture of Anacystis nidulans strain I 14 (nitB2). (a) Frequency of reversion to wild type of the nitB2 marker. (b) Synchronous growth (O) and survival after mutagenesis $(\bigcirc)$. Survival was determined as cell count after the mutated sample had been incubated to permit segregation of revertants.

peak is not open to any conventional statistical analysis. However, since mutation frequency was determined at intervals of no less than $5 \mathrm{~min}$, the error on the map positions may be as great as $5 \mathrm{~min}$. Unlike the previous map of this organism (Asato \& Folsome, 1970), the markers span the whole period of the DNA replication cycle. The map positions of the markers $p m b A$ (polymyxin $\mathrm{B}$ resistance), yelA (yellow pigmentation) and bluA (blue pigmentation) agree closely with those of similar markers on the map described by Asato \& Folsome (I970) as shown in Fig. 5. The position of the sna (snake) marker and the fil (filamentous) marker do not correspond, although they both exhibit a filamentous phenotype. However, Kunisawa \& Cohen-Bazire (1970) have described two types of filamentous mutants of $A$. nidulans, class I and class II: the Sna mutants resemble the class I type while all the Fil mutants were of the class II type.

Multiple peaks of mutagenesis. For some markers such as bio-2, pmb, yel and blu more than one peak of mutation was observed, indicating that mutation at more than one locus could give rise to the same phenotype. Mutations to yellow pigmentation mapped at three sites designated yelA, yelB and yelC (Fig. 4), while mutations to blue pigmentation and polymyxin $B$ resistance mapped at two. Although yellow mutants are frequently defective in the assimilation of nitrate, none of the yellow loci corresponded to either of the genes involved in the reduction of nitrate (nit $A$ and nit $B$ ), suggesting either that there were further 


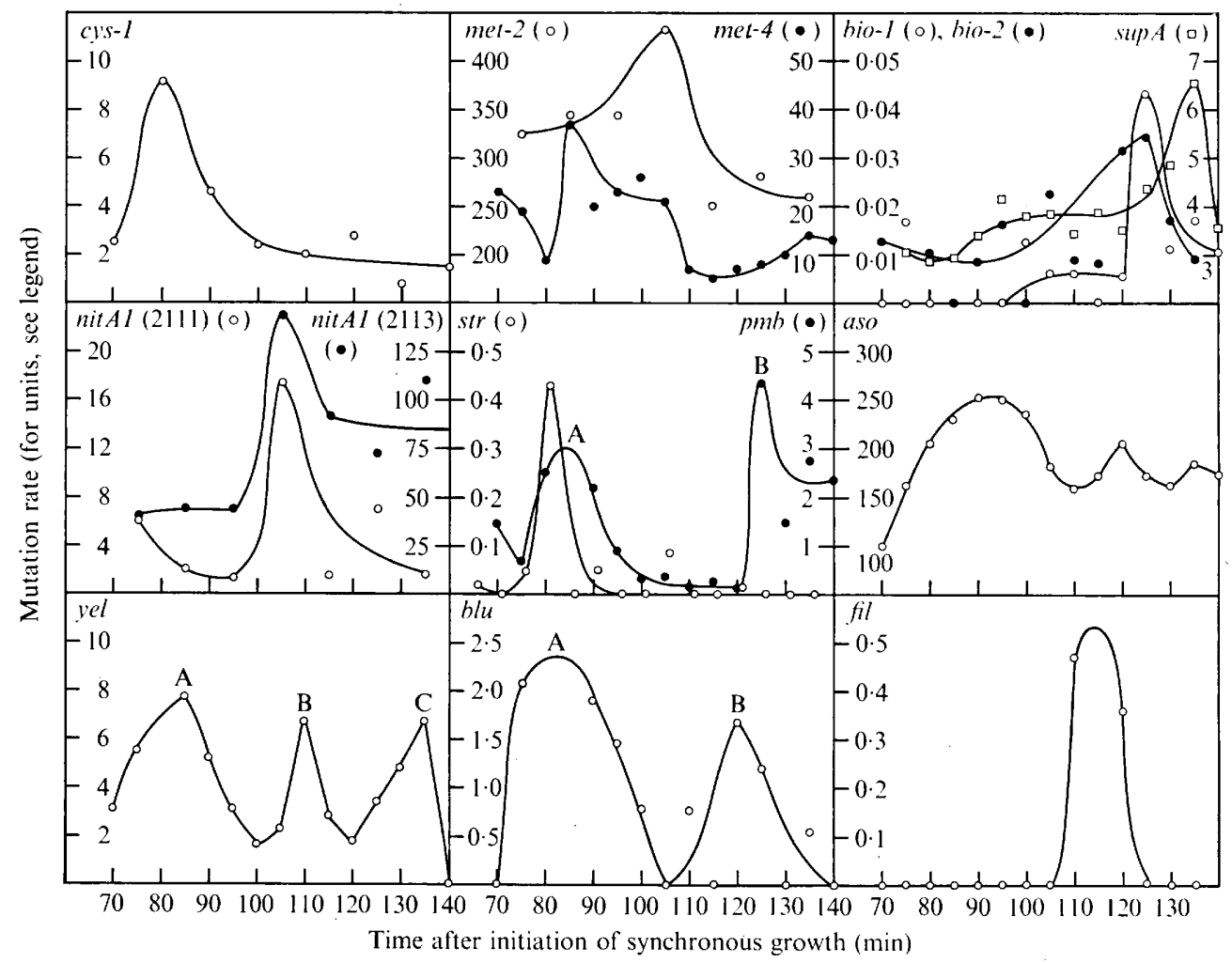

Fig. 4. Sequential mutagenesis of synchronized cultures of Anacystis nidulans. Mutation rates were expressed as follows: met-4, bio-r, bio-2, supA, nitAI (2III), str, pmb and aso, as mutants/1 ${ }^{6}$ survivors; $y e l$, blu and $f i l$, as mutants $/ \mathrm{IO}^{3}$ propionate-resistant mutants; cys- - , met-2 and nit $A I$ (2II3), as mutants $/ \mathrm{ml}$. Scoring mutations in different ways had no effect on the time at which the peak of mutation occurred.

genes involved in the reduction of nitrate or that these mutants were defective in pigment synthesis.

Mapping of the bio-2 marker resulted in two types of revertants which mapped at different sites (Fig. 4): large dark colonies resembling the wild type, and small pale colonies. The former were presumed to be true revertants while the latter appeared to be suppressed mutants which mapped at a different site designated $\sup A$. It was not possible to analyse these genetically to establish whether the original mutation had been suppressed in the latter. Suppressor mutations were not observed when any other auxotrophic markers were mapped.

Mutations to proprionate resistance mapped at one site only ( $p r p$ ) and this was in agreement with the proposal of Smith \& Lucas (I97I) that resistance was brought about by mutation in the gene specifying acetate thiokinase. Unless there were several copies of this gene at different sites along the genome, propionate resistance was expected to map at one site only. 


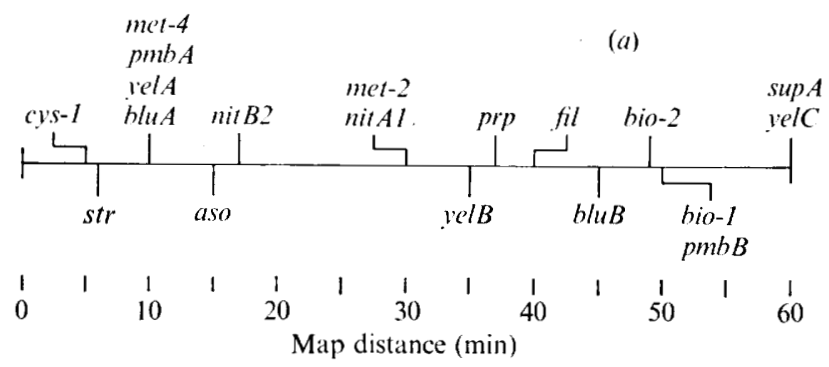

(b)

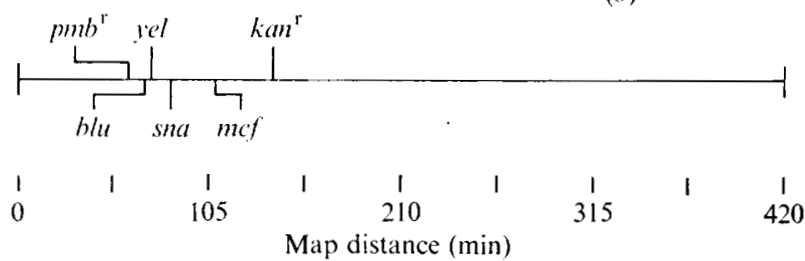

Fig. 5. (a) The temporal genetic map of Anacystis nidulans. aso denotes mutation to cyanophage AS-I resistance; the other genetic symbols are explained in the text. (b) For comparison, the map obtained by Asato \& Folsome (1970), drawn to the same scale, is shown.

\section{DISCUSSION}

The increased growth rates of synchronized cultures compared with exponential cultures may have been at the expense of pools of precursors formed during the induction period. Herdman et al. (1970) have shown that, in A. nidulans, normal cell metabolism continues for a short time after the beginning of the induction period and it is possible that after the cessation of macromolecular synthesis, pools of precursors continue to be built up for some time in the dark.

On the return to normal growth conditions synchronized growth at increased rates may occur at the expense of these pools. Increase in growth rates of synchronized cultures have been observed in E. coli (Barner \& Cohen, 1956), Lactobacillus acidophilus (Burns, 1959) and Schizosaccharomyces pombe (Sando, 1963), and have been ascribed to unbalanced growth resulting from synchronization (Mitchison, 197I). Whether synchronized growth of $A$. nidulans was balanced or unbalanced was not considered to be of importance for the purposes of temporal genetic mapping, since it was only necessary for a culture to go through one cycle of synchronized DNA replication irrespective of the state of growth of the organism. However, it must be assumed that the velocity of the replication fork(s) remains constant during this cycle of replication.

Enhanced mutagenesis at the replication point by EMS can be explained in terms of repair processes. In addition to photoreactivation (Asato \& Folsome, I969) there is now good evidence for the existence of dark repair processes in $A$. nidulans. Caffeine and acriflavine are believed to prevent excision of u.v.-induced damage (Setlow, 1964; Clarke, 1967), causing increased sensitivity to the mutagen. Under conditions preventing photoreactivation, increased sensitivity to u.v. light as a result of caffeine treatment (Asato, 1972) and acriflavine treatment (Singh, I968; Singh, Kumar \& Prakash, 1969) of $A$. nidulans has been observed. In addition, a u.v.-sensitive mutant of $A$. nidulans has been shown to be insensitive to the effect of acriflavine (Singh, 1968), indicating that it may lack an excision repair mechanism. 
(a)
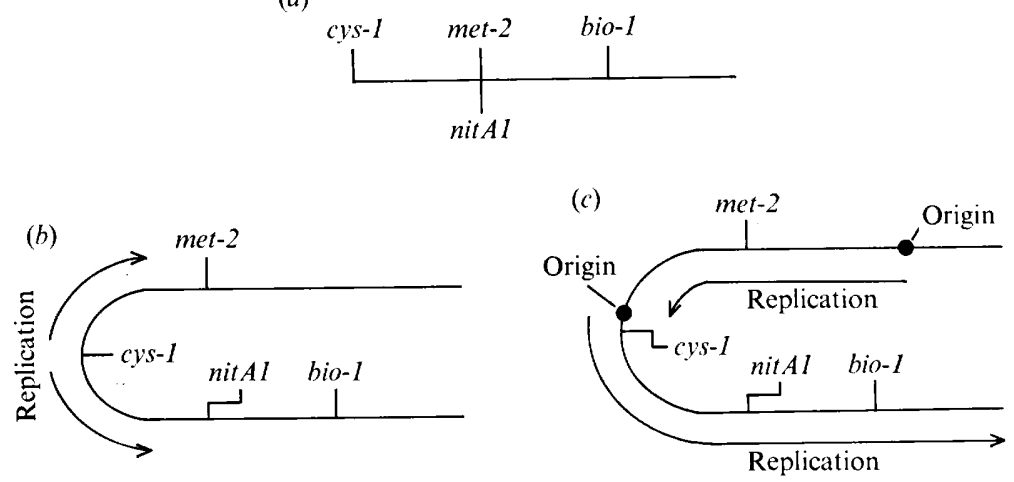

Fig. 6. (a) The temporal genetic map of Anacystis nidulans; (b) and (c) represent the conventional genetic map (Herdman, 1973) on which two possible modes of replication can be superimposed. Either $(b)$ the genome is replicated bidirectionally from a single origin, or $(c)$ there is more than one origin and replication proceeds in one direction.

It has been shown that EMS damage in $A$. nidulans cannot be photoreactivated but can be repaired by a dark repair process which is sensitive to caffeine (Delaney \& Carr, unpublished data). Any mutational damage induced during sequential mutagenesis of synchronized cultures can presumably be repaired by this process. However, any damage immediately ahead of the replication fork is likely to be replicated before it can be repaired by this repair mechanism. Although the mutation frequency of a gene increased as it was replicated there was no concurrent decrease in survival (Fig. 3), indicating that there was some repair during and immediately after gene replication even though this resulted in enhanced mutagenesis. This situation is analogous to post-replication repair in $E$. coli (Witkin, 1969) where u.v.-induced damage can be repaired after the replication of damaged regions of DNA by a mechanism which tends to introduce mutations. The repair of replicated damage in $A$. nidulans by a similar process would explain enhanced mutagenesis of the replication point without any loss in viability. Once the replication fork has passed, any further damage to a gene could be repaired by the excision repair process before the next round of replication and so the mutation frequency would return to normal. In this way a peak in mutation frequency of a gene would result as that gene was replicated. The possible existence of an error-prone repair process in blue-green algae similar to post-replication repair is supported by the isolation of a mutant which was sensitive to u.v. light but showed reduced mutability (Zhevner \& Shestakov, 1972). This mutant resembles the exr mutants of $E$. coli which are defective in post-replication repair (Witkin, 1969). Where a mutagen acts preferentially at the replication fork it can be predicted that if a mutation at a particular site is selected for, there will be an increased frequency of mutation in genes adjacent to this site. Thus clusters of closely linked mutations will arise. This has been observed both with NTG (Guerola, Ingraham \& Cerdá-Olmedo, I971) and EMS (Lindegren, Courtis \& Schult, I968).

Transformation in $A$. nidulans mediated by naturally-occurring nucleic acids (Herdman, 1973) has enabled a conventional genetic map for five markers to be constructed. This is shown in Fig. 6. The temporal genetic map can be compared with this map with respect to four markers, nitAI, cys-I, met-2 and bio-I, on the basis of which two modes of replication can be proposed (Fig. 6). Either replication starts from a single initiation point and is bidirectional, or it is unidirectional and starts from several initiation points. At present it is 
not possible to distinguish between these two models, but since bidirectional replication is now well established in other organisms (Huberman \& Riggs, I968; Masters \& Broda, 197I ; Danna \& Nathans, I972; Gyurasits \& Wake, 1973) the former model is favoured.

S.F.D. acknowledges a research studentship from the University of Liverpool; this work was supported in part by the Science Research Council.

\section{REFERENCES}

AsATo, Y. (I972). Isolation and characterisation of ultraviolet-light sensitive mutants of the blue-green alga Anacystis nidulans. Journal of Bacteriology 110, 1058-1064.

Asato, Y. \& Folsome, C. E. ( 1969 ). Mutagenesis of Anacystis nidulans by $N$-methyl- $N^{\prime}$-nitro- $N$-nitrosoguanidine and UV irradiation. Mutation Research 8, 531-536.

Asato, Y. \& Folsome, C. E. (1970). Temporal genetic mapping of the blue-green alga, Anacystis nidulans. Genetics 65, 407-419.

BARner, H. D. \& Cohen, S. S. ( 1956 ). Synchronisation of cell division of a thymineless mutant of Escherichia coli. Journal of Bacteriology 72, I I 5-1 23.

Bird, R. E., Louarn, J., Martuscelli, J. \& Caro, L. (I 972). Origin and sequence of chromosome replication in Escherichia coli. Journal of Molecular Biology 70, 549-566.

BURNS, V. W. (1959). Synchronised cell division and DNA synthesis in a Lactobacillus acidophilus mutant. Science, New York 129, 566-567.

Burton, K. (1956). A study of the conditions and mechanism of the diphenylamine reaction for the colorimetric estimation of deoxyribonucleic acid. Biochemical Journal 62, 315-323.

Caro, L. G. \& BerG, C. M. (1968). Chromosome replication in some strains of Escherichia coli K12. Cold Spring Harbor Symposia on Quantitative Biology 33, 559-573.

Cerdí-Olmedo, E., Hanawalt, P. C. \& Guerola, N. (1968). Mutagenesis of the replication point by nitrosoguanidine: map and pattern of replication of the Escherichia coli chromosome. Journal of Molecular Biology 33, 705-719.

Cl,ARKE, C. H. (1967). Caffeine- and amino acid-effects upon trp ${ }^{+}$revertant yield in U.V.-irradiated $h c r^{+}$ and $h r^{-}$mutants of E. coli $\mathrm{B} / \mathrm{r}$. Molecular and General Genetics 99, 97-I 08 .

Craig, I. W., Leach, C. K. \& Carr, N. G. (I969). Studies with deoxyribonucleic acid from blue-green algae. Archiv für Mikrobiologie 65, 218-227.

Cutler, R. G. \& Evans, J. E. (1967). Relative transcription activity of different segments of the genome throughout the cell division cycle of Escherichia coli. The mapping of ribosomal and transfer RNA and the determination of the direction of replication. Journal of Molecular Biology 26, 9I-105.

Danna, K. J. \& Nathans, D. (1972). Bidirectional replication of Simian virus 40 DNA. Proceedings of the National Academy of Sciences of the United States of America 69, 3097-3I00.

Guerola, N., Ingraham, J. L. \& Cerdá-Olmedo, E. (I97I). Induction of closely linked multiple mutations by nitrosoguanidine. Nature New Biology 230, I 22-125.

Gyurasits, E. B. \& WAKE, R. G. (I973). Bidirectional chromosome replication in Bacillus subtilis. Journal of Molecular Biology 73, 55-63.

Herdman, M. (1973). Transformation in the blue-green alga Anacystis nidulans and the associated phenomenon of mutation. In Bacterial Transformation, pp. 369-386. Edited by L. J. Archer. London: Academic Press.

Herdman, M., Delaney, S. F. \& Carr, N. G. (I973). A new medium for the isolation and growth of auxotrophic mutants of the blue-green alga Anacystis nidulans. Journal of General Microbiology 79, 233-237.

Herdman, M., Faulkner, B. M. \& Carr, N. G. (1970). Synchronous growth and genome replication in the blue-green alga Anacystis nidulans. Archiv für Mikrobiologie 73, 238-249.

Hohlfeld, R. \& Vielmetter, W. (1973). Bidirectional growth of the E. coli chromosome. Nature New Biology 242, I30-I 32.

Huberman, J. A. \& Riggs, A. D. (1968). On the mechanism of DNA replication in mammalian chromosomes. Journal of Molecular Biology 32, 327-34I.

JYsSUM, K. ( 1 969). Origin and sequence of chromosome replication in Neisseria meningitidis: influence of a genetic factor determining competence. Journal of Bacteriology 99, 757-763. 
Kunisawa, R. \& COHEN-BAZIRE, G. (1970). Mutations of Anacystis nidulans that affect cell division. Archiv für Mikrobiologie 7I, 49-59.

Lindegren, G., Courtis, W. S. \& Schult, E. E. (1968). Linked genes arising among multiple mutants in EMS-treated Saccharomyces. Canadian Journal of Genetics and Cytology 1o, 470-472.

LOVELESS, A. (1959). The influence of radiomimetic substances on deoxyribonucleic acid synthesis and function studied in Escherichia coli/phage systems. III. Mutation of $\mathrm{T}_{2}$ bacteriophage as a consequence of alkylation in vitro: the uniqueness of ethylation. Proceedings of the Royal Society B 150, 497-508.

MASTERS, M. \& BRODA, P. (1971). Evidence for the bidirectional replication of the Escherichia coli chromosome. Nature New Biology 232, I37-I 40.

Masters, M. \& Pardee, A. B. (I965). Sequence of enzyme synthesis and gene replication during the cell cycle of Bacillus subtilis. Proceedings of the National Academy of Sciences of the United States of America $54,64-70$.

Mitchison, J. M. (1971). The Biology of the Cell Cycle, pp. 36-38. Cambridge University Press.

Nishioka, Y. \& EISENSTARK, A. (I970). Sequence of genes replicated in Salmonella typhimurium as examined by transduction techniques. Journal of Bacteriology 102, 320-333.

Sabatier, A., Louarn, J. M. \& Sicard, A. M. (1972). Replication séquentielle du chromosome du pneumocoque. Comptes rendus hebdomadaire des séances de l'Academie des sciences $\mathrm{D} 275$, I $187-1189$.

SAfFerman, R. S. \& Morris, M. E. (I964). Growth characteristics of the blue-green algal virus LPP-I. Journal of Bacteriology 88, 77I-775.

SANDo, N. (1963). Biochemical studies on the synchronised culture of Schizosaccharomyces pombe. Journal of General and Applied Microbiology 9, 233-24I.

Setlow, R. B. (1964). Physical changes and mutagenesis. Journal of Cellular and Comparative Physiology 64, S. I, $5 \mathrm{I}-68$.

SiNGH, H. N. (I968). Effect of acriflavine on ultra-violet sensitivity of normal, ultra-violet sensitive and ultra-violet resistant strains of a blue-green alga, Anacystis nidulans. Radiation Botany 8, 355-36r.

Singh, H. N., Kumar, H. D. \& Prakash, G. (1969). Postirradiation modification of ultraviolet-sensitivity of normal and nitrofurazone-resistant strains of the blue-green alga Anacystis nidulans. Radiation Botany 9, I05-IIO.

Smith, A. J. \& LuCAS, C. (197I). Propionate resistance in blue-green algae. Biochemical Journal 124, $23 \mathrm{p}-24 \mathrm{p}$.

Stonehill, E. H. \& Hutchison, D. J. (I966). Chromosomal mapping by means of mutational induction in synchronous populations of Streptococcus faecalis. Journal of Bacteriology 92, 136-143.

Vielmetter, W., MesSer, W. \& SCHÜTte, A. (I 968 ). Growth direction and segregation of the E. coli chromosome. Cold Spring Harbor Symposia on Quantitative Biology 33, 585-598.

WITKIN, E. M. (I969). The role of DNA repair and recombination in mutagenesis. Proceedings of the XII International Congress of Genetics 3, 225-245.

YoshikaWA, H. \& SUEOKA, N. (1963). Sequential replication of Bacillus subtilis chromosome. I. Comparison of marker frequencies in exponential and stationary growth phases. Proceedings of the National Academy of Sciences of the United States of America 49, 559-566.

ZheVNER, V. D. \& Shestakov, S. V. (I972). Studies on the ultraviolet-sensitive mutants of the blue-green alga Synechocystis aquatilis Sanv. Archiv für Mikrobiologie 86, 349-360. 